\title{
High-precision morphology: bifocal 4D-microscopy enables the comparison of detailed cell lineages of two chordate species separated for more than 525 million years
}

Thomas Stach ${ }^{1 *}$ and Chiara Anselmi ${ }^{2}$

\begin{abstract}
Background: Understanding the evolution of divergent developmental trajectories requires detailed comparisons of embryologies at appropriate levels. Cell lineages, the accurate visualization of cleavage patterns, tissue fate restrictions, and morphogenetic movements that occur during the development of individual embryos are currently available for few disparate animal taxa, encumbering evolutionarily meaningful comparisons. Tunicates, considered to be close relatives of vertebrates, are marine invertebrates whose fossil record dates back to 525 million years ago. Life-history strategies across this subphylum are radically different, and include biphasic ascidians with free swimming larvae and a sessile adult stage, and the holoplanktonic larvaceans. Despite considerable progress, notably on the molecular level, the exact extent of evolutionary conservation and innovation during embryology remain obscure.

Results: Here, using the innovative technique of bifocal 4D-microscopy, we demonstrate exactly which characteristics in the cell lineages of the ascidian Phallusia mammillata and the larvacean Oikopleura dioica were conserved and which were altered during evolution. Our accurate cell lineage trees in combination with detailed three-dimensional representations clearly identify conserved correspondence in relative cell position, cell identity, and fate restriction in several lines from all prospective larval tissues. At the same time, we precisely pinpoint differences observable at all levels of development. These differences comprise fate restrictions, tissue types, complex morphogenetic movement patterns, numerous cases of heterochronous acceleration in the larvacean embryo, and differences in bilateral symmetry.

Conclusions: Our results demonstrate in extraordinary detail the multitude of developmental levels amenable to evolutionary innovation, including subtle changes in the timing of fate restrictions as well as dramatic alterations in complex morphogenetic movements. We anticipate that the precise spatial and temporal cell lineage data will moreover serve as a high-precision guide to devise experimental investigations of other levels, such as molecular interactions between cells or changes in gene expression underlying the documented structural evolutionary changes. Finally, the quantitative amount of digital high-precision morphological data will enable and necessitate software-based similarity assessments as the basis of homology hypotheses.
\end{abstract}

Keywords: Ascidian, Development, Evolution, Larvacean, Neural crest, Tunicate

\footnotetext{
* Correspondence: thomas.stach@hu-berlin.de

${ }^{1}$ Institut für Biologie, Kompetenzzentrum Elektronenmikroskopie,

Humboldt-Universität zu Berlin, Philippstrasse 13, Haus 1410115 Berlin,

Germany

Full list of author information is available at the end of the article
}

(C) 2015 Stach and Anselmi. Open Access This article is distributed under the terms of the Creative Commons Attribution 4.0 International License (http://creativecommons.org/licenses/by/4.0/), which permits unrestricted use, distribution, and reproduction in any medium, provided you give appropriate credit to the original author(s) and the source, provide a link to the Creative Commons license, and indicate if changes were made. The Creative Commons Public Domain Dedication waiver (http://creativecommons.org/publicdomain/zero/1.0/) applies to the data made available in this article, unless otherwise stated. 


\section{Background}

The succession of billions of generations of inherited ontogenies with slight modifications from the ontogenies of their predecessors comprises the process of evolution $[1,2]$. Comprehension of the evolution of divergent developmental trajectories requires detailed comparisons of embryologies at appropriate levels [3-6]. Cell lineages as detailed and accurate visualizations based on fourdimensional (4D)-microscopy of cleavage patterns, tissue fate restrictions, and morphogenetic movements that occur during the development of individual embryos are currently available for few disparate animal taxa [7-12]. In addition, it is noteworthy that most of the available detailed cell lineages derive from protostomian (sensu [13]) animals encumbering evolutionarily broader comparisons. Tunicates are marine invertebrates considered to be close relatives of vertebrates [14] and whose fossil record dates back to 525 million years ago (Mya) $[15,16]$. Life-history strategies across this subphylum are radically different, and include biphasic ascidians with free swimming larvae and a sessile adult stage, the directly developing holoplanktonic larvaceans, and the equally holoplanktonic thaliaceans with some of the most complex life-cycles in the animal kingdom [17]. Despite considerable progress, notably on the molecular level, the exact extent of evolutionary conservation and innovation especially on other organismic levels during embryology remain obscure and leave room for speculation $[18,19]$. Here, we overcome the limitations in microscopy imposed by the cellular and acellular coverings of ascidian eggs and embryos by using the innovative technique of bifocal 4D-microscopy. In a comparative approach we demonstrate exactly which characteristics in the cell lineages of the ascidian Phallusia mammillata and the previously studied larvacean Oikopleura dioica [20] were conserved and which were altered during evolution. Our accurate cell lineage trees combined with the exact three-dimensional reconstructions of cell positions identify clearly the conserved correspondences in cell position, identity, cell movements, and fate restrictions in several cell lines while at the same time precisely pinpointing differences observable at all levels of development. These differences comprise fate restrictions, tissue types, complex morphogenetic movement patterns, bilateral asymmetry, and numerous cases of heterochronous acceleration in the larvacean embryo. Our results demonstrate in extraordinary detail the multitude of developmental levels amenable to evolutionary innovation. We anticipate that the detailed cell lineage data combined with the accurate relative spatial representation of cells will moreover serve as a high-precision guide to devise experimental investigation of other levels, such as molecular interactions between cells or changes in gene expression underlying the documented structural evolutionary changes of ontogenetic processes. Finally, the sheer amount of digital high-precision morphological data will enable and necessitate new attempts to formulate software-based, quantifiable similarity assessments as the basis of homology hypotheses.

\section{Results and discussion}

Bifocal 4D-microscopy considerably extends the range of focus compared to conventional 4D-microscopy [11] and is therefore useful in larger embryos, more opaque embryos, or in embryos that are invested with protective coverings. At least the latter, and usually a combination of these limiting factors, are present in ascidian embryos. Ascidian eggs and embryos are protected during their development by an outer layer of follicle cells, a chorion membrane, and an inner layer of chorion cells $[21,22]$. The simultaneous comparative analysis of two tunicate species using the same analytical software (Simi Biocell, Simi Reality Motion Systems GmbH, Unterschleißheim, Germany) and a similar recording technique, and therefore the same level of precision, allowed for an improved re-analysis of the previously reported cell lineage of the larvacean Oikopleura dioica (Fig. 1a), enabling improvements over the original cell lineage results reported in [20] for the larvacean, while adding a cell lineage in an ascidian species, Phallusia mammillata (Fig. 1b), at unprecedented precision. Based on this comparative approach, it was possible to identify the progeny of A6.1 in O. dioica as purely endodermal and descendants of B8.12/B8.12 as probable heart precursor cells. Because no mesenchymal cells, such as blood cells or tunic cells, are present in the adult larvacean and because the heart, surrounded by purely epithelial cells, is the only mesodermal structure in the adult larvacean [23, 24], we suspect that all descendants of B5.1/B5.1 are purely endodermal in their respective fates. However, because we could not rule out the presence of mesenchymal cells in the $4 \mathrm{~h} 30$ min old hatchling on the basis of the present light-microscopic investigation, we cautiously refrained from denoting all B5.1/ $\underline{\text { 55.1 }}$ descendants as endodermally fate restricted (Fig. 1a).

In order to facilitate comparisons between trees, we used Conklin's nomenclature for both species [20, 25]. Conklin also devised a set of rules that assures comparability that we followed in our analyses and applied to the tree $[25,26]$ depictions (for more information, see "Methods"). To distinguish between the cells from both sides, we again used Conklin's nomenclature by underlining cell names referring to the right side of the embryo.

While the ascidian cell lineage tree is highly symmetrical (Fig. 1b), the larvacean cell lineage tree shows a marked asymmetry in the lineage of the notochord. On the left side, A8.1 as a descendant of A6.1 is already restricted to an endodermal fate. On the right side, A8.1 gives rise to additional notochordal cells. 


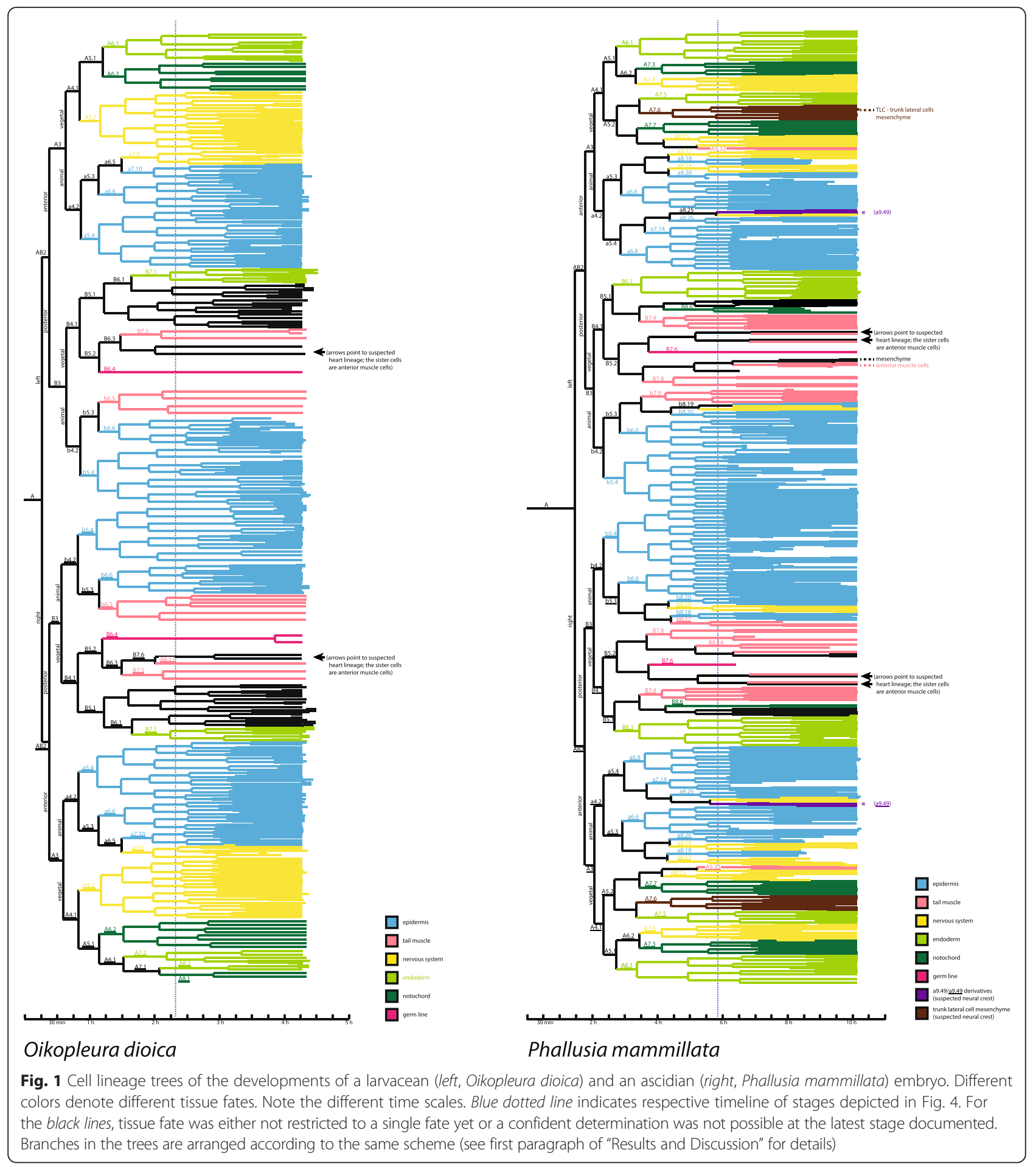

The direct side-by-side comparison of the 4Dmicroscopical cell lineage trees of the ascidian $P$. mammillata and the larvacean $O$. dioica (Fig. 1) reveals exact correspondences and differences of various degrees. In the following, we discuss examples of these different relations. It should be noted, that more examples are documented in the extensive supplementary material accompanying this publication online.

\section{Exact correspondences of cell identity and fate}

Exact correspondences in relative position, cell identity, and fate in both species are observed in several cells. 
Cells A6.1/ $\underline{\mathrm{A} 6.1}$ and $\mathrm{B} 7.1 / \underline{\mathrm{B} 7.1}$ are already restricted to become the progenitors of endodermal cellular fates by the sixth and seventh generation. In both species the respective cells are situated at the rim of the blastopore just prior to gastrulation: anteriorly in A6.1/A6.1, posteriorly in B7.1/B7.1. While the endodermal fate is already restricted, the descendants of A6.1/A6.1 in both species end up forming the anterolateral part of the intestinal larval tract, whereas cells B7.1/B7.1 show a slightly different migration pattern between the two species (Additional files 1 and 2). In the larvacean the descendants of B7.1/ $\underline{B} .1$ form part of the endodermal strand (shown for B7.1 in Additional file 2). whereas in the ascidian embryo the descendants of B7.1/B7.1 form ventral trunk endoderm and it is B7.2 that eventually gives rise to endodermal strand cells (shown for B7.1 and B7.2 in Additional file 2). Similarly, the prospective epidermis cells in the ectodermal lines a6.6/a6.6, a6.8/a6.8, b6.6/b6.6, b5.4/b5.4, the prospective notochordal cells A7.3/A7.3, and the prospective neural tube cells A8.15/A8.15 correspond to each other in the two species in their respective relative positions, their fate restrictions, and their locations in the cell lineage trees (Figs. 1 and 2; Additional files 3, 4, 5, 6, 7, 8, 9 and 10).

\section{Heterochronic shifts}

Besides cases of exact correspondences, however, in some other cell lines correspondences are more relaxed.
While, for example, the relative positions in the cell lineage trees of muscle cell lines, pericardium cell lines, and germ cells are similar, fate restrictions occur comparatively later in the ascidian (Figs. 1 and 2; Additional files 11, 12 and 13). For example, the germ cell line is the sister lineage to a line that gives rise to pericardium and anterior somatic muscle cells in both species. This separation, however, occurs at the sixth generation in the larvacean (B6.4/B6.4) and at the seventh generation in the ascidian (B7.6/B7.6) (Fig. 1). If the supposition mentioned above that descendants of B5.1/B5.1 might in fact be entirely endodermal, this would be another case of an earlier fate restriction, interestingly with the daughter cells B6.1/B6.1 still being a case of exact correspondence. This general trend towards a relatively earlier fate restriction in the larvacean embryo leads to a tighter coupling of cell lineage and fate restrictions in $O$. dioica. For example, notochord cells in the left side derive from A6.2 in the larvacean, but from A7.3, A7.7, and B8.6 in the ascidian (Figs. 1 and 2). Similar patterns can be seen in the fate restrictions of nervous system, endoderm, and musculature. These cases where a specific, cohesive larval tissue originates in several separate cell lines indicate in the bifurcating cell lineage tree representation that cell fates might depend on regional cellular interactions in the ascidian, as has been shown in the ascidian Ciona intestinalis [27]. While our data are

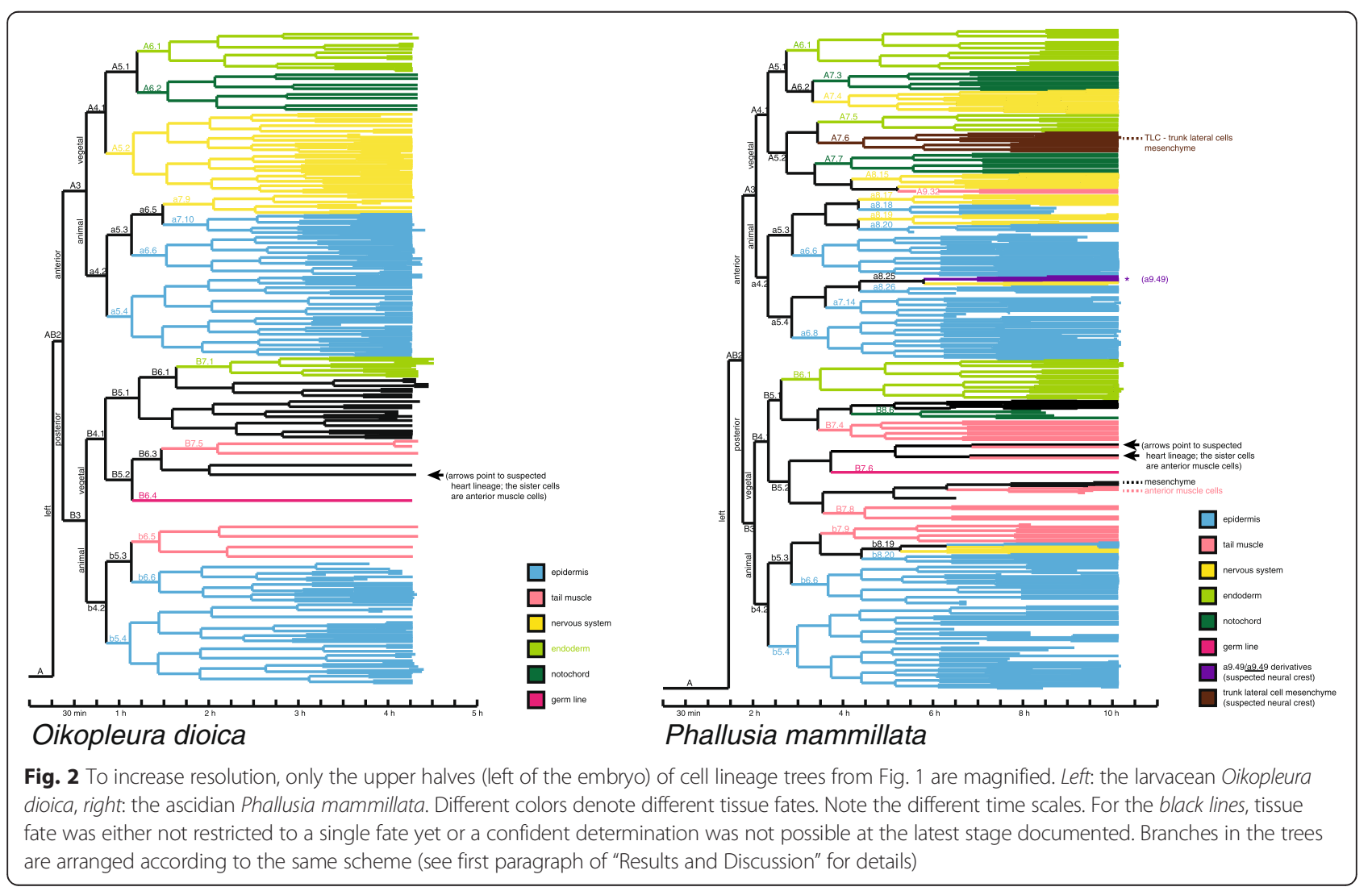


compatible with the hypothesis that in larvaceans cell lineage determines fate to a large extent, regional inductions are not ruled out, but should be tested in laboratory experiments.

\section{Morphogenetic movements - gastrulation}

We also analyzed complex morphogenetic movements such as gastrulation at single cell resolution by comparing cellular movement profiles (Fig. 3). The starting point of these profiles are the precise positional relations of individual cells but because of the lower resolution in time cellular movements within a certain time bracket can be determined only roughly. Nevertheless, we found that the general movement patterns of individual cells that are positioned in a corresponding way around the blastopore at the onset of gastrulation (upper row in Fig. 3) are highly similar, but that the movement occurs one to two rounds of divisions earlier in the larvacean. Moreover, identities according to cell genealogy are not conserved in each case even when position and fate are retained, revealing again evolutionary changes. For example, in the case of cells A6.3 in larvacean and A7.4 in ascidian, we show that the cells are situated at the posterior end of the embryo at the onset of gastrulation (Fig. 3) and give rise to nervous system cells in the neural tube (Additional files 7, 8 and 9) but differ in their location in the cell lineage trees as indicated by their names and in their respective positions in the larval nervous systems.

\section{Morphogenetic movements - neurulation}

The morphogenetic process that results in the typical neural tube of chordates is called neurulation ([28, 29]; see also [30]). With the example of neurulation, the spatiotemporal resolution of comparative cell lineage analyses shows that the relative timings of morphogenetic events are also susceptible to evolutionary changes. Whereas in the ascidian embryos neurulation follows gastrulation, the two processes occur almost simultaneously in larvacean embryology. Thus the highly ordered and stereotypic pattern of prospective nervous system cells in a neural plate at the anterior border of the blastopore in ascidian embryos is not present in the larvacean (Fig. 4). Instead the prospective nervous system cells are already arranged to form an elongated rod-like array along the anteroposterior axis during gastrulation that is pronouncedly narrow at the anterior end at cell generation 7 (Fig. 3 and Additional file 9). While, therefore, a similarly stereotyped pattern of the prospective nervous system cells arranged in a neural plate does not occur in the larvacean embryo of a comparable stage (late gastrula; Fig. 4) and the number of cells is considerably smaller, an overall similarity exists. For example, the prospective neural tube cells are similar in their anterodorsal position and their anteroposterior order. Interestingly, the anterior portion of the prospective nervous system in embryos of $O$. dioica is more bulbous than the posterior one very early on during ontogeny (at the eighth cell division, Additional file 10), thus showing a characteristic that occurs in considerably later stages in the ascidian embryo (at the

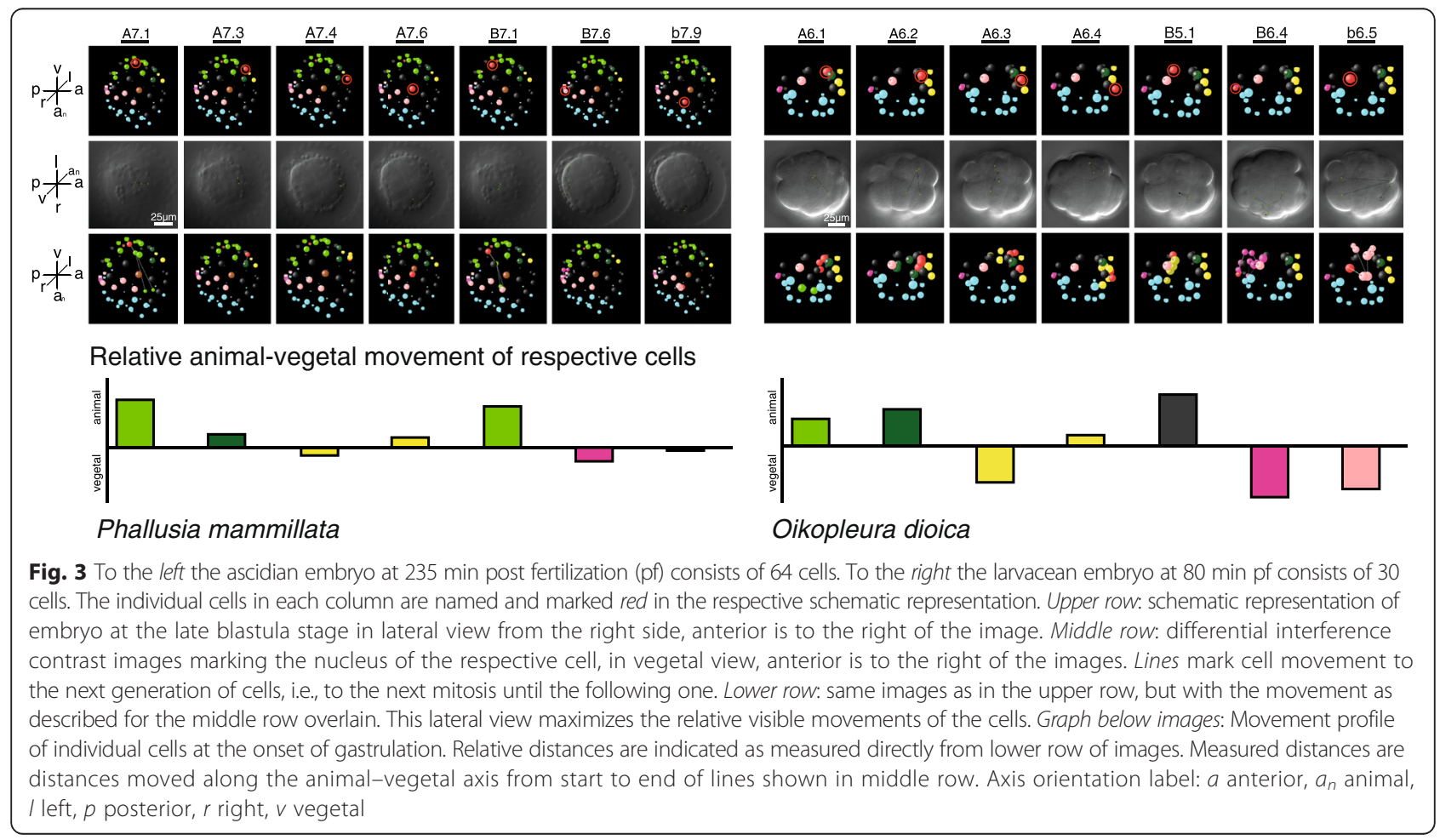




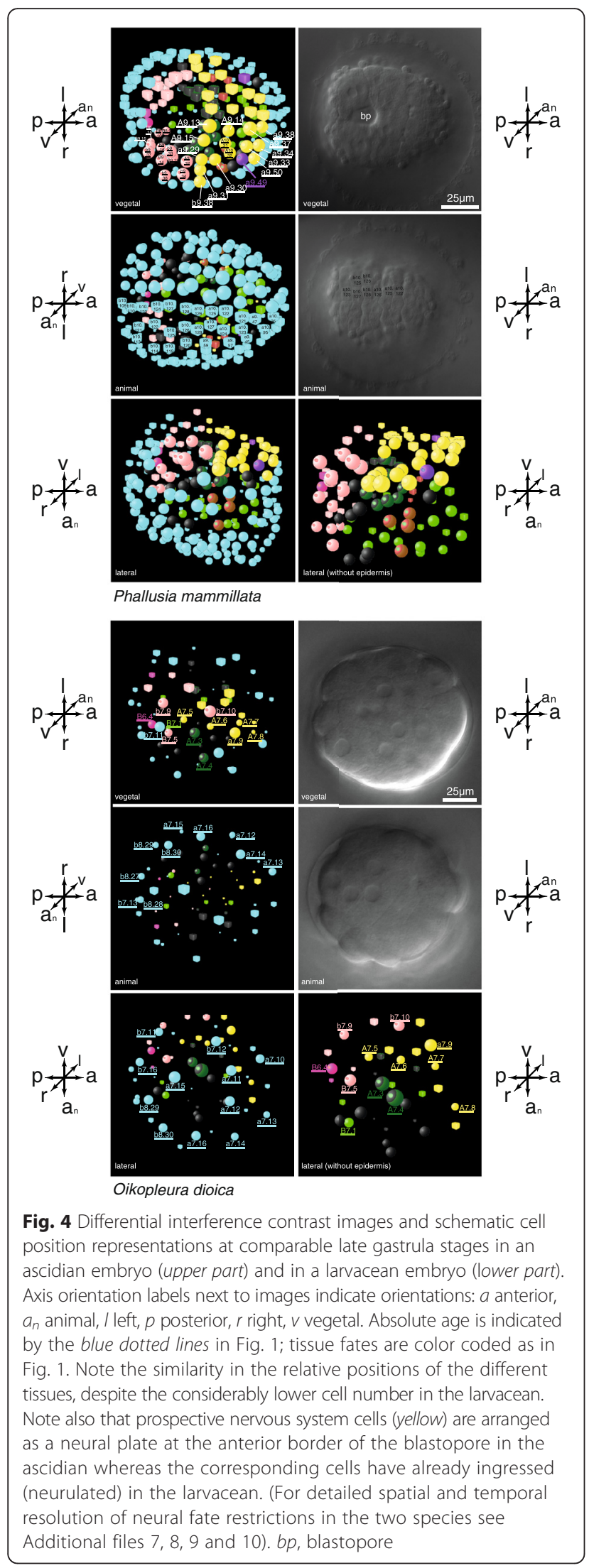

tenth/eleventh generation of the prospective nervous system cells; see the movie available at [31]). An interesting difference occurring during neurulation in the two species is the bilaterally symmetric arrangement of cells in the ascidian larva, whereas in the larvacean embryo the prospective nervous system cells of both sides intermingle and form a complete dorsal neural tube with a lower number of cells than in the ascidian (Additional file 6: Figure S6, Additional file 7: Figure S7, Additional file 8: Figure S8, Additional file 9: Figure S9 and Additional file 10: Figure S10; [20]).

\section{Loss of sub-lineages and cellular novelties}

The juxtaposition of comparable stages in the two tunicates shows that besides the temporal discrepancy of events, the ascidian embryo has undergone eight or nine mitoses in most lineages when neurulation commences, whereas the larvacean has undergone seven. This means that at this stage there are more than twice the number of cells in the ascidian ( $c=181)$ than in the larvacean ( $c=63$ ). Concomitant to the higher number of cells, ascidian embryos possess additional tissue types that are not present in larvaceans, such as the trunk lateral cells (TLCs). TLCs are the descendants of cells A7.6/A7.6 and form a conspicuous cluster of lateral mesenchymatic cells in the trunk of tadpole and larval stages of ascidians (Additional file 14). Because other chordates, such as cephalochordates [32-34], hagfishes [35, 36], or ammocoetes [37, 38], possess mesenchymatic cells during early stages in ontogeny, this outgroup comparison indicates that larvaceans are evolutionarily derived in regard to this trait. TLCs, that is, the descendants of cells A7.6/A7.6, have been suggested to be homologous to vertebrate neural crest [39]. Alternatively, Abitua and colleagues hypothesized that cells a9.49/a9.49 and their descendants correspond to vertebrate neural crest cells [40]. Whereas TLCs are absent in larvaceans, a9.49/a9.49 are present but their descendent cells are anterior epidermis cells and not bordering the dorsal anterior neural tube as is the case in the ascidian embryo (Fig. 4). Thus the precise position of the descendants of a9.49/a9.49 in the ascidian tadpole clearly corresponds to the definition of neural crest cells in the zebrafish anatomy ontology (see [41]), therefore supporting the hypothesis suggested by Abitua and colleagues [40].

\section{Detailed comparisons of individual cells}

The power of bifocal 4D-microscopy becomes evident when individual cells, their respective fates, and movement patterns at different developmental stages are compared (Fig. 5 and Additional file). For instance, b7.9 and descending cells in the animal half of the gastrulae are situated between prospective epidermis cells yet develop into posterolateral tail muscle cells in both species, although 

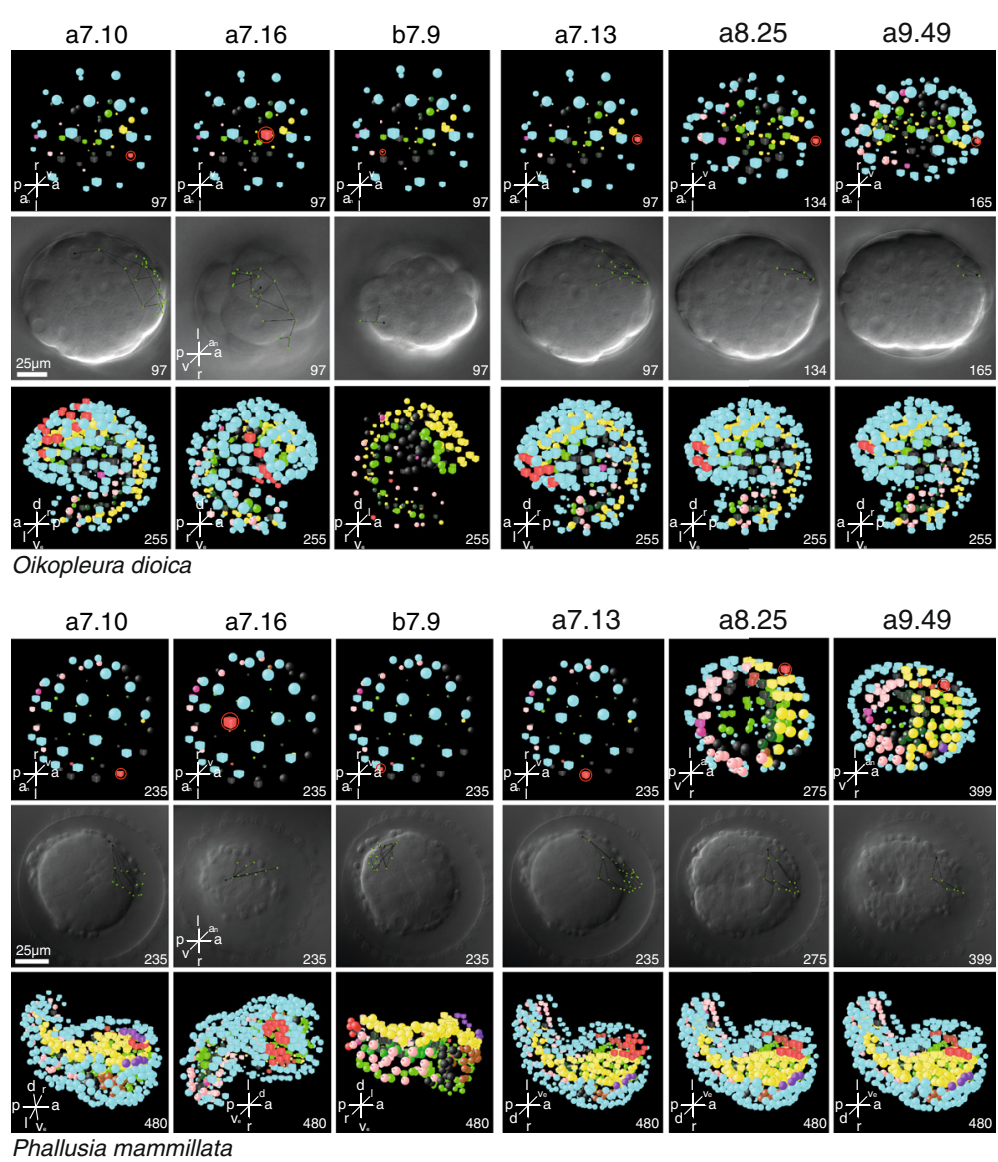

a9.49
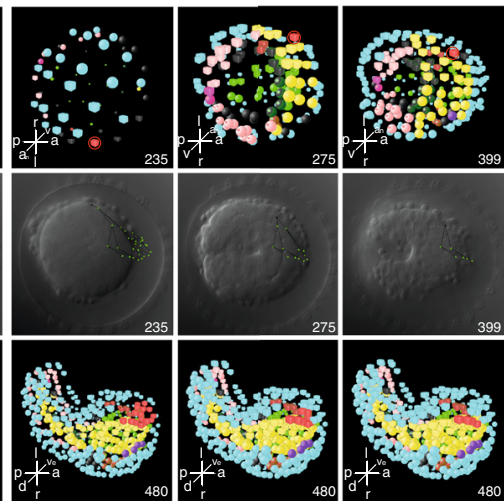

Fig. 5 Selected tracings of individual cells from the animal half of the embryo. The cells indicated on top of each column are marked red in the schematic representation and the descendants of the respective cells are seen in red in the lower rows. The intermediary Differential interference contrast image shows the cell divisions and cell movements of the respective cells. Numbers are minutes post fertilization. Nomarski images are all in the same orientation. Axis orientation labels in images indicate orientations: $a$ anterior, $a_{n}$ animal, $d$ dorsal, $/$ left, $p$ posterior, $r$ right, $v$ vegetal, $v e$ ventral. Upper panel: Oikopleura dioica. Lower panel: Phallusia mammillata. The right-most column details the mitotic history of cell line a9.49 that has been hypothesized to be homologous to vertebrate neural crest cells

the bending of the tail in relation to the trunk is considerably more pronounced and the tail is affected by an ongoing torsion in the larvacean embryo (Fig. 5, Additional files 3 and 4; see also [20]). In other cases of animal cells, such as a7.10, the descendants of which become anterodorsal epidermis cells in both species, the similarity also comprises the movement pattern from an anterior animal position in the gastrula stage (see Fig. 5). (Numerous and detailed additional examples, also from other germ layers, can be found in the supporting information accompanying this article online). Again, it becomes evident that at all levels certain characteristics are highly similar between the species, whereas others differ to various degrees.

Building on the pioneering study by Conklin on Styela partita [25] that has been considerably expanded by Nishida [42, 43] for Halocynthia roretzi-who used a tedious injection technique to trace cell fates-several modern studies analyzing cell fates in specific tissues of Ciona intestinalis [27, 44-46] documented on the one hand that cell lineages in ascidian species seemed conserved, while stating that "comparative analysis is a difficult exercise due to the current poor anatomical description." [47]. Our application of bifocal 4Dmicroscopy for the first time revealed the precise and almost complete cell lineage of an ascidian embryo up to the early tadpole stage (between stage 17 and 18 in the ANISEED database: http://www.aniseed.cnrs.fr/aniseed/ anatomy/find_devstage), enabling detailed comparisons with the improved re-analyzed cell lineage of an appendicularian species.

In comparing our detailed documentation of cell lineages of $P$. mammillata with available information on cell lineages in other ascidian species, we found more similarities to the described cell lineages of $C$. intestinalis $[27,44-46]$ and $H$. roretzi $[42,43]$ than to the only 
publication of a cell lineage of $P$. mammillata itself [48]. In their cell fate tabulation (table 1 in [48], p. 196), Zalokar and Sardet combined available data from different species and, using injection of a fluorescent marker in $P$. mammillata, corrected several previous misconceptions $[49,50]$, notably in the lines becoming muscle cells. For example, these authors realized that cells B7.6/B7.6 do not give rise to muscle cells, but fell short of determining the actual fate of this cell as the germ line cell. This realization came only later in comparative studies using $H$. roretzi as a model $[43,51,52]$. Because other errors had not been corrected and because the study by Zalokar and Sardet remained the only one on the cell lineage of $P$. mammillata, our results are closer to the published cell lineages of $H$. roretzi and $C$. intestinalis. For example, contrary to the lineage published by Zalokar and Sardet [48], A7.6/A7.6 do not give rise to notochord but to TLCs as in C. intestinalis [27] and H. roretzi [43]. Another example are the B8.6/B8.6 cells, which are tabulated as mesenchymal in fate for P. mammillata by Zalokar and Sardet but that we found, in agreement with Nishida [43] and Lemaire [27], become notochordal cells. On the other hand, we note minor differences in some lineages to these studies. Both Nishida and Lemaire describe the fate of B7.7/B7.7 cells as mesenchymal, whereas we found the descendants become muscle and mesenchyme. Whether this discrepancy is due to real differences in the lineages of the different species or due to limitations in resolution remains to be verified. The fine grain of our cell lineage observations also allows us to relate these data with the even finer morphological detail of confocal laser scanning microscopy-derived morphological descriptions of certain ascidian embryonic stages that recently became available [53, 54].

\section{Evolutionary considerations}

Although the exact phylogeny of Tunicata remains controversial [15, 55-57], most paleontological studies indicate that the diversification of Tunicata dates back to the early Cambrian (ca. 525 Mya) [58]. Thus, the precision of our cell lineage data opens an entirely new horizon for evolutionary analyses and interpretation. We could reveal detailed similarities with single cell resolution pertaining to different levels of potential homologies, such as cleavage tree pattern, fate restriction, morphogenetic movements, timing, or orientation of planes of cell divisions. We demonstrated that each of these levels is susceptible to changes and conclude that there is no a priori reason to expect one level to be less prone to evolution than another. Indeed the many levels of evolvability of embryonic development are a stark reminder that evolutionary analyses cannot afford to neglect organismal levels.

\section{Cell lineage indicates cellular signaling}

Detailed cell lineage data can moreover serve as a high-precision guide to devise experimental approaches to investigate other levels as well, such as molecular interactions between cells, changes in gene expression, but also studies designed to unravel the accompanying molecular changes underlying the documented structural evolutionary changes. For example, from the cell lineage tree we would predict that the determination of nervous system cell fate in several of the comparatively late restricting nervous system cell lines such as a8.17/a8.17 and a8.19/a8.19 (descendants of a4.2/ $\underline{\mathrm{a} 4.2}$ ) depend on regional factor signaling whereas this might not be the case for A7.4/A7.4 (descendants of A4.1/A4.1). And indeed, because neural cell lineages in ascidians were available relatively early on [46], it could be demonstrated that neural descendants of A4.1/A4.1 develop autonomously, whereas signaling from this source is necessary for the a4.2/a4.2 descendants to assume a neural fate [47]. We predict that regional induction is similarly necessary for neural fate determination in A8.15/ A8.15. Moreover, we argue that the restriction to neural fate in a7.9/a7.9 in the larvacean embryo depends on regional signaling as well and that the reduction of such signaling in several cell lines led to the streamlined cell lineage tree documented in the larvacean $O$. dioica.

\section{Conclusion}

Bifocal 4D-microscopy overcomes the limitations imposed on light microscopic observations in ascidian embryos by the extensive extra embryonic covers of a developing embryo. While many molecular studies remove these coverings [51], removing these covers results in some ontogenetic changes, such as shape of epidermis cells and formation of larval tunic, compared to the wild-type development $[59,60]$. Thus bifocal 4D-microscopy can amend these shortcomings and considerably expand our knowledge of tunicate ontogeny at a detailed cellular level. While the present paper focuses on the comparative findings rather than on the methodological advancement, it is obvious that 4D-microscopy in a comparative framework allows for and necessitates new analytical tools and poses new and exciting challenges [26, 61]. An important challenge relates to the notion of homology: with the huge amount of detailed and precise information present in the accumulated data, it becomes obvious that we need to develop software tools that can guide us through the many layers of similarities, including the positional relational information, the movement and cleavage pattern, temporal information of all the observed events, fate restriction patterns, and similarities in underlying gene regulatory networks, and visualize or quantify similarity arguments 
in support of different homology hypotheses. Because homology is the central concept in evolutionary comparative biology, addressing this challenge with appropriate data mining and analytical tools has to become a priority in the burgeoning field of visual computer analyses.

\section{Methods}

Fundamentals of 4D-microscopy are described by Schnabel et al. [11]. Individual $O$. dioica embryos recorded by Stach et al. [20] were re-analyzed comparatively for the present study. (In contrast to ascidian embryos, $O$. dioica embryos do not possess follicle or test cells and therefore conventional 4D-microscopy suffices.) Fourcell, eight-cell, or sixteen-cell embryos of $P$. mammillata were recorded using bifocal 4D-recordings. Bifocal 4Dmicroscopy was developed by Dr. Ralf Schnabel (Technical University, Braunschweig) in cooperation with Zeiss. Essentially, in a Zeiss Examiner (Zeiss, Jena, Germany) D1 microscope the condenser was replaced with a second optical microscope unit, including a second objective and camera (Additional file 15). The microscope was equipped with an extended internal focus drive (500 $\mu \mathrm{m}$; (Physical Instruments, Karlsruhe, Germany)) used to move the stage to record a $\mathrm{z}$ series with two PCO pixelfly cameras, documenting each focal plane from above and below. Images were compressed with a wavelet function (Lurawave) LuraTech, Remscheid, Germany. The microscope was controlled with a software programmed by K. Schulz and R. Schnabel. Embryos were recorded at $18{ }^{\circ} \mathrm{C}$ in a thermocontrolled room; in addition the upper objective was equipped with a thermoconstant cooling ring. Recordings of three different embryos stemming from three different parental pairs were analyzed using SIMI BioCell software (SIMI) Simi Reality Motion Systems, Unterschleissheim, Germany. Starting with a four-cell or eight-cell embryo, 140 images were recorded every $60 \mathrm{~s}$ from 70 planes $1.7 \mu \mathrm{m}$ apart with the two cameras. A complete scan consisted of 1,000 scans, resulting in a database comprising 140,000 images. Of the approximately $16 \mathrm{~h}$ of development recorded, $8 \mathrm{~h}$ were analyzed in detail. For cell nomenclature, we used Conklin's system for both species [25] (a translation table to the larvacean nomenclature used by Delsman [62] is given in [20]). For the determination of a cell's name and for the tree representation of the cell lineages we also used Conklin's set of rules. The daughter cell that is situated closer to the vegetal pole after mitosis received the lower number and, in the tree depiction, is represented by the outer branch $[25,26]$. In cases where both cells are at the same height along the animal-vegetal axis, the cell closer to the anterior received the lower number and is represented by the outer branch in the anterior half oft he embryo; in the posterior half oft he embryo it is the cell closer to the posterior that received the lower number and is represented by the outer branch. In cases where the daughter cells are also identical in their respective position along the antero-posterior axis, the more distal cell was given the lower number and represented by the outer branch (see figures 133 and 134 in [25]). To distinguish between the cells from both sides, we again used Conklin's suggestion and underlined cell names referring to the cells on the right side of the embryo.

P. mammillata adults were obtained through the service Modèles Biologiques (ModBio) from the Centre de Resources Biologiques Marines at the Station Biologique Roscoff (France). In each experiment, two individuals were cross-fertilized in vitro as described [51] and normally developing embryos were mounted for microscopic analysis. The latter citation reports results from cell lineage tracing in P. mammillata. Our detailed documentation of cell lineages of this very species shows more similarities to the described cell lineages of $C$. intestinalis and $H$. roretzi than to the description of the cell lineage of $P$. mammillata [51]. Complete datasets including complete stacks of differential interference contrast images and SIMI BioCell-files are deposited on www.morphdbase.de along with Additional files and can be downloaded from there.

\section{Availability of supporting data}

The complete datasets supporting the results of this article are available in the MorphDBase repository as zipped archives.

The database consisting of approximately 140,000 images of a recording of the ontogenetic development of a Phallusia mammillata embryo has been separated into two packages, representing the images from the upper and lower camera respectively.

zip-compressed files of the complete scan of the development of P. mammillata, including Simi-Biocell analysis files:

www.morphdbase.de/?T_Stach_20151112-M-47.1 www.morphdbase.de/?T_Stach_20151112-M-46.1

zip-compressed file of complete scan of the development of O. dioica, including Simi-Biocell analysis files:

www.morphdbase.de/?T_Stach_20151112-M-45.1

A supplementary movie at www.morphdbase.de/?T_ Stach_20151020-M-13.1 shows the ontogeny and detailed cell lineages of the two tunicate species $P$. mammillata, an ascidian, and $O$. dioica, a larvacean. The two species have drastically different life histories and ecologies, yet the cell lineage pattern shows remarkable similarities.

Additional movies of tracings of specific cells can be requested from the first author.

High resolution versions of supplementary figures are available as indicated in the captions to the additional files. 


\section{Additional files}

Additional file 1: Phallusia mammillata. Analytical cell lineage tracing of individual endodermal cells between blastula stage (3 h 55 min pf) and early tadpole stage ( $10 \mathrm{~h} 6 \mathrm{~min}$ pf). A higher resolution version of this figure is hosted on MorphDBase at: www.morphdbase.de/?T_Stach_ 20151119-M-58.1. (PDF 4316 kb)

Additional file 2: Oikopleura dioica. Analytical cell lineage tracing of individual endodermal cells between blastula stage (1 h 37 min pf) and early larval stage (4 h 15 min pf). A higher resolution version of this Fig. is hosted on MorphDBase at: www.morphdbase.de/?T_Stach_20151119-M-59.1. (PDF 2348 kb)

Additional file 3: Phallusia mammillata. Analytical cell lineage tracing of individual animal-half cells between blastula stage (3 h 55 min pf) and early tadpole stage ( $10 \mathrm{~h} 6 \mathrm{~min}$ pf). A higher resolution version of this figure is hosted on MorphDBase at: www.morphdbase.de/?T_Stach_ 20151119-M-60.1. (PDF 5844 kb)

Additional file 4: Oikopleura dioica. Analytical cell lineage tracing of individual animal-half cells between blastula stage ( 1 h 37 min pf) and early larval stage (4 h 15 min pf). A higher resolution version of this figure is hosted on MorphDBase at: www.morphdbase.de/?T_Stach_20151119-M61.1. (PDF $5425 \mathrm{~kb}$ )

Additional file 5: Phallusia mammillata. Analytical cell lineage tracing of individual notochordal cells between blastula stage (3 h 55 min pf) and early tadpole stage (10 h 6 min pf). A higher resolution version of this figure is hosted on MorphDBase at: www.morphdbase.de/?T_Stach_ 20151119-M-62.1. (PDF 6767 kb)

Additional file 6: Oikopleura dioica. Analytical cell lineage tracing of individual notochordal cells between blastula stage (1 h 17 min pf) and early larval stage (4 h 15 min pf). A higher resolution version of this figure is hosted on MorphDBase at: www.morphdbase.de/?T_Stach_20151119M-63.1. (PDF $2830 \mathrm{~kb}$ )

Additional file 7: Phallusia mammillata. Analytical cell lineage tracing of individual nervous system cells between blastula stage (3 h 55 min pf) and early tadpole stage (10 h 6 min pf). A higher resolution version of this figure is hosted on MorphDBase at: www.morphdbase.de/

?T_Stach_20151119-M-64.1. (PDF 2998 kb)

Additional file 8: Phallusia mammillata. Analytical cell lineage tracing of individual nervous system cells between gastrula stage (5 h $38 \mathrm{~min}$ pf) and early tadpole stage (10 h 6 min pf). A higher resolution version of this figure is hosted on MorphDBase at: www.morphdbase.de/?T_Stach_ 20151119-M-65.1. (PDF 8904 kb)

Additional file 9: Oikopleura dioica. Analytical cell lineage tracing of individual nervous system cells between earlier blastula stage (57 min pf)and early larval stage (4 h 15 min pf). A higher resolution version of this figure is hosted on MorphDBase at: www.morphdbase.de/?T_Stach_ 20151119-M-66.1. (PDF 4700 kb)

Additional file 10: Oikopleura dioica. Analytical cell lineage tracing of individual nervous system cells between later gastrula stage ( 2 h 12 min pf) and early larval stage (4 h 15 min pf). A higher resolution version of this figure is hosted on MorphDBase at: www.morphdbase.de/?T_Stach_ 20151119-M-67.1. (PDF 3697 kb)

Additional file 11: Phallusia mammillata. Analytical cell lineage tracing of individual muscle cells between blastula stage ( 3 h 55 min pf) and early tadpole stage (10 h 6 min pf). A higher resolution version of this figure is hosted on MorphDBase at: www.morphdbase.de/?T_Stach_ 20151119-M-68.1. (PDF 4703 kb)

Additional file 12: Phallusia mammillata. Analytical cell lineage tracing of individual muscle cells between gastrula stage ( 5 h 38 min pf) and early tadpole stage (10 h $6 \mathrm{~min}$ pf). A higher resolution version of this figure is hosted on MorphDBase at: www.morphdbase.de/?T_Stach_ 20151119-M-69.1. (PDF 5654 kb)

Additional file 13: Oikopleura dioica. Analytical cell lineage tracing of individual muscle cells between blastula stage ( 1 h 17 min pf) and early larval stage (4 h 15 min pf). A higher resolution version of this figure is hosted on MorphDBase at: www.morphdbase.de/?T_Stach_20151119-M70.1. (PDF 3696 kb)

Additional file 14: Phallusia mammillata. Analytical cell lineage tracing of individual trunk lateral cells (TLCs) between blastula stage (3 h 55 min pf) and early tadpole stage ( $10 \mathrm{~h} 6 \mathrm{~min}$ pf). A higher resolution version of this figure is hosted on MorphDBase at: www.morphdbase.de/?T_Stach_ 20151119-M-71.1. (PDF 721 kb)

Additional file 15: A Bifocal 4D-microscope. B Higher magnification of the lower objective that replaces the condenser in the bifocal 4Dmicroscope. C Adult Phallusia mammillata. D-G Pictures of removal of gametes from a hermaphroditic P. mammillata individual during the fertilization process in the laboratory. A higher resolution version of this figure is hosted on MorphDBase at: www.morphdbase.de/?T_Stach_ 20151119-M-72.1. (PDF 3653 kb)

\section{Competing interests}

None of the authors have any competing interests.

\section{Authors' contributions}

TS designed the study, recorded the ontogenies, carried out cell lineage analyses, cut the movie, compiled figures, and wrote the manuscript. CA carried out cell lineage analysis, compiled figures, and created movies of P. mammillata ontogenies. Both authors read and approved the final manuscript.

\section{Acknowledgements}

Financial support by the German Research Foundation (DFG-grants STA655/4 \& STA655/5) and by ERASMUS is gratefully acknowledged.

\section{Author details}

${ }^{1}$ Institut für Biologie, Kompetenzzentrum Elektronenmikroskopie, Humboldt-Universität zu Berlin, Philippstrasse 13, Haus 1410115 Berlin, Germany. 'Dipartimento di Biologia, Università degli Studi di Padova, Via Ugo Bassi 58/B, 35131 Padova, Italy.

Received: 18 June 2015 Accepted: 8 December 2015

Published online: 23 December 2015

\section{References}

1. Garstang W. The theory of recapitulation: a critical re-statement of the biogenetic law. Linnean J Zool. 1921;35:81-101.

2. Kalinka AT, Tomancak P. The evolution of early animal embryos: conservation or divergence? Trends Ecol Evol. 2012;27:385-93.

3. Nielsen C. Larval nervous systems: true larval and precocious adult. J Exp Biol. 2015;218(4):629-36.

4. Richter S, Wirkner CS. A research program for evolutionary morphology. J Zool Syst Evol Res. 2014:52(4):338-50.

5. Scholtz G. Versuch einer analytischen Morphologie. Bildwelten des Wissens. 2013:9(2):30-44.

6. Wray GA. The evolution of cell lineage in echinoderms. Am Zool. 1994;34:353-63.

7. Hejnol A, Martindale M. Acoel development supports a simple planula-like urbilaterian. Philos T R Soc B. 2008:363:1493-501.

8. Alwes F, Scholtz G. Cleavage and gastrulation of the euphausiacean Meganyctiphanes norvegica (Crustacea, Malacostraca). Zoomorphology 2004;123(3):125-37.

9. Hejnol A, Martindale MQ Henry JO. High-resolution fate map of the snail Crepidula fornicata: the origins of ciliary bands, nervous system, and muscular elements. Dev Biol. 2007;305(1):63-76.

10. Hejnol A, Schnabel R. The eutardigrade Thulinia stephaniae has an indeterminate development and the potential to regulate early blastomere ablations. Development. 2004;132:1349-61.

11. Schnabel R, Hutter H, Moermann D, Schnabel H. Assessing normal embryogenesis in Caenorhabditis elegans using a 4D microscope: variability of development and regional specification. Dev Biol. 1997;184:234-65.

12. Schulze J, Schierenberg E. Evolution of embryonic development in nematodes. EvoDevo. 2011;2:18.

13. Dunn CW, Giribet G, Edgecombe GD, Hejnol A. Animal phylogeny and its evolutionary implications. Annu Rev Ecol Evolut Syst. 2014;45:371-95. 
14. Delsuc F, Brinkmann $H$, Chourrout D, Philippe $H$. Tunicates and not cephalochordates are the closest living relatives of vertebrates. Nature. 2006;439:965-8

15. Fedonkin MA, Vickers-Rich $P$, Swalla BJ, Trusler $P$, Hall M. A new metazoan from the Vendian of the White Sea, Russia, with possible affinities to the ascidians. Paleontol J. 2012;46(1):1-11.

16. Shu D, Isozaki Y, Zhang X, Han J, Maruyama S. Birth and early evolution of metazoans. Gondwana Res. 2014;25(3):884-95.

17. Lemaire P. Evolutionary crossroads in developmental biology: the tunicates. Development. 2011;138(11):2143-52.

18. Onai T, Irie N, Kuratani $\mathrm{S}$. The evolutionary origin of the vertebrate body plan: the problem of head segmentation. Annu Rev Genomics Hum Genet. 2014;15(1):443-59.

19. Satoh N, Tagawa K, Lowe CJ, Yu J-K, Kawashima T, Takahashi H, et al. On a possible evolutionary link of the stomochord of hemichordates to pharyngeal organs of chordates. Genesis. 2014;52(12):925-34.

20. Stach T, Winter J, Bouquet J-M, Chourrout D, Schnabel R. Embryology of a planktonic tunicate reveals traces of sessility. Proc Natl Acad Sci. 2008;105(20):7229-34.

21. Burighel P, Cloney RA. Urochordata: Ascidiacea. In: Harrison FW, Ruppert EE, editors. Microscopic anatomy of Invertebrates Hemichordata, Chaetognatha, and the invertebrate chordates, vol. 15. New York: Willey-Liss, Incorporation; 1997. p. 221-347.

22. Satoh N. Developmental biology of ascidians. Cambridge: Cambridge University Press; 1994.

23. Stach T. Anatomy of the trunk mesoderm in tunicates: homology considerations and phylogenetic interpretation. Zoomorphology. 2009;128:97-109.

24. Lohmann H. Erste Klasse der Tunicaten. Appendiculariae. In: Krumbach T, editor. Handbuch der Zoologie, vol. 5.2. Tunicata. Berlin: Walter de Gruyter \& Co; 1956. p. 15-202

25. Conklin EG. Organization and cell lineage of the ascidian egg. J Acad Natl Sci Phila. 1905;XIII(Part 1):1-119. plates I-XII.

26. Nishida $H$, Stach $T$. Cell lineages and fate maps in tunicates: conservation and modification. Zool Sci. 2014:31(10):645-52

27. Lemaire P. Unfolding a chordate developmental program, one cell at a time: invariant cell lineages, short-range inductions and evolutionary plasticity in ascidians. Dev Biol. 2009;332(1):48-60.

28. Lowery LA, Sive $H$. Strategies of vertebrate neurulation and a re-evaluation of teleost neural tube formation. Mech Devel. 2004;121:1189-97.

29. Harrington MJ, Hong E, Brewster R. Comparative analysis of neurulation: first impressions do not count. Mol Reprod Dev. 2009;76:954-65.

30. https://zin.org/action/ontology/term-detail/GO:0001841

31. www.morphdbase.de/?T_Stach_20151020-M-13.1

32. Hirakow R, Kajita N. Electron microscopic study of the development of amphioxus, Branchiostoma belcheri tsingtauense, the neurula and larva. Acta Anat Nippon. 1994;69:1-13.

33. Stach T. Microscopic anatomy of developmental stages of Branchiostoma lanceolatum (Cephalochordata, Chordata). Bonn Zool Monogr. 2000:47:1-111.

34. Stach T. Chordate phylogeny and evolution: a not so simple three-taxon problem. J Zool. 2008;276(2):117-41.

35. Oisi Y, Ota KG, Kuraku S, Fujimoto S, Kuratani S. Craniofacial development of hagfishes and the evolution of vertebrates. Nature. 2013:493(7431):175-80.

36. Ota KG, Kuraku S, Kuratani S. Hagfish embryology with reference to the evolution of the neural crest. Nature. 2007;446:672-5.

37. Kuratani S, Kuraku S, Murakami Y. Lamprey as an evo-devo model: lessons from comparative embryology and molecular phylogenetics. Genesis. 2002;34:175-83.

38. Kuratani S, Murakami Y, Nobusada Y, Kusakabe R, Hirano S. Developmental fate of the mandibular mesoderm in the lamprey, Lethenteron japonicum: comparative morphology and development of the gnathostome jaw with special reference to the nature of the trabecula cranii. J Exp Zool. 2004;302B:458-68

39. Jeffery WR, Chiba T, Krajka FR, Deyts C, Satoh N, Joly J-S. Trunk lateral cells are neural crest-like cells in the ascidian Ciona intestinalis: insights into the ancestry and evolution of the neural crest. Dev Biol. 2008;324(1):152-60.

40. Abitua PB, Wagner E, Navarrete IA, Levine M. Identification of a rudimentary neural crest in a non-vertebrate chordate. Nature. 2012:492:104-8.

41. http://zfin.org/action/ontology/term-detail/ZDB-TERM-100331-43

42. Nishida $\mathrm{H}$. Cell division pattern during gastrulation of the ascidian Halocynthia roretzi Dev Growth Differ. 1986;28:191-201.
43. Nishida $\mathrm{H}$. Cell lineage analysis in ascidian embryos by intracellular injection of a tracer enzyme. Dev Biol. 1987;121:526-41.

44. Davidson B, Shi W, Levine M. Uncoupling heart cell specification and migration in the simple chordate Ciona intestinalis. Development. 2005;132(21):4811-8.

45. Hudson C, Ba M, Rouvière C, Yasuo H. Divergent mechanisms specify chordate motoneurons: evidence from ascidians. Development. 2011;138(8):1643-52

46. Cole AG, Meinertzhagen IA. The central nervous system of the ascidian larva: mitotic history of cells forming the neural tube in late embryonic Ciona intestinalis. Dev Biol. 2004;271(2):239-62.

47. Lemaire $P$, Bertrand $V$, Hudson C. Early steps in the formation of neural tissue in ascidian embryos. Dev Biol. 2002;252:151-69.

48. Zalokar M, Sardet C. Tracing of cell lineage in embryonic development of Phallusia mammillata (Ascidia) by vital staining of mitochondria. Dev Biol. 1984;102:195-205

49. Swalla BJ, Smith AB. Deciphering deuterostome phylogeny: molecular, morphological and palaeontological perspectives. Philos Trans R Soc Lond B. 2008;363:1557-68

50. García-Bellido DC, Lee MSY, Edgecombe GD, Jago JB, Gehling JG, Paterson JR. A new vetulicolian from Australia and its bearing on the chordate affinities of an enigmatic Cambrian group. BMC Evol Biol. 2014;14:214.

51. Christiaen L, Wagner E, Shi W, Levine M. Isolation of sea squirt (Ciona) gametes, fertilization, dechorionation, and development. Cold Spring Harb Protoc. 2009;2009(12):pdb.prot5344.

52. Thompson H, Shimeld SM. Transmission and scanning electron microscopy of the accessory cells and chorion during development of Ciona intestinalis type $B$ embryos and the impact of their removal on cell morphology. Zool Sci. 2015;32:217-22.

53. Cloney RA, Cavey MJ. Ascidian larval tunic - extra-embryonic structures influence morphogenesis. Cell Tissue Res. 1982;222:547-62.

54. Whittaker JR. Cytoplasmic determinants of tissue differentiation in the Ascidian egg. In: Subtelny S, Konigsberg IR, editors. Determinants of spatial organization. New York: Academic; 1979. p. 29-51.

55. Mancuso V. L'uovo di Ciona intestinalis (Ascidia) osservato al microscopio electronico. I. II cell-lineage. Acta Embryologica Experimentalia. 1969;12:231-255

56. Iseto T, Nishida H. Ultrastructural studies on the centrosome-attracting body: electron-dense matrix and its role in unequal cleavages in ascidian embryos. Develop Growth Differ. 1999:41:601-9.

57. Nakamura MJ, Terai J, Okubo R, Hotta NK, Oka K. Three-dimensional anatomy of the Ciona intestinalis tail bud embryo at single-cell resolution. Dev Biol. 2012;372:274-84

58. Veeman M, Reeves W. Quantitative and in toto imaging in ascidians: working toward an image-centric systems biology of chordate morphogenesis. Genesis 2015:53:143-59.

59. Tsagkogeorga G, Turon X, Hopcroft R, Tilak M, Feldstein T, Shenkar N, et al. An updated $18 \mathrm{~S}$ rRNA phylogeny of tunicates based on mixture and secondary structure models. BMC Evol Biol. 2009:9:187.

60. Govindarajan AF, Bucklin A, Madin LP. A molecular phylogeny of the Thaliacea. J Plankton Res. 2011:33:843-53.

61. Vogt L, Nickel M, Jenner RA, Deans AR. The need for data standards in zoomorphology. J Morphol. 2013:274(7):793-808.

62. Delsman HC. Beiträge zur Entwicklungsgeschichte von Oikopleura dioica. Verhandelingen uit het Rijksinstituut voor het Onderzoek der Zee. 1910;3:1-24.

\section{Submit your next manuscript to BioMed Central and we will help you at every step:}

- We accept pre-submission inquiries

- Our selector tool helps you to find the most relevant journal

- We provide round the clock customer support

- Convenient online submission

- Thorough peer review

- Inclusion in PubMed and all major indexing services

- Maximum visibility for your research

Submit your manuscript at www.biomedcentral.com/submit 